\title{
Noble metal-free upgrading of multi-unsaturated biomass derivatives at room temperature: Silyl species enable reactivity
}

Li, Hu; Zhao, Wenfeng; Dai, Wenshuai; Long, Jingxuan; Watanabe, Masaru; Meier, Sebastian; Saravanamurugan, Shunmugavel; Yang, Song; Riisager, Anders

\author{
Published in: \\ Green Chemistry \\ Link to article, DOI: \\ 10.1039/C8GC02934B \\ Publication date: \\ 2018 \\ Document Version \\ Peer reviewed version \\ Link back to DTU Orbit
}

Citation (APA):

Li, H., Zhao, W., Dai, W., Long, J., Watanabe, M., Meier, S., Saravanamurugan, S., Yang, S., \& Riisager, A. (2018). Noble metal-free upgrading of multi-unsaturated biomass derivatives at room temperature: Silyl species enable reactivity. Green Chemistry, 20(23), 5327-5335. https://doi.org/10.1039/C8GC02934B

\section{General rights}

Copyright and moral rights for the publications made accessible in the public portal are retained by the authors and/or other copyright owners and it is a condition of accessing publications that users recognise and abide by the legal requirements associated with these rights.

- Users may download and print one copy of any publication from the public portal for the purpose of private study or research.

- You may not further distribute the material or use it for any profit-making activity or commercial gain

- You may freely distribute the URL identifying the publication in the public portal 


\section{Green}

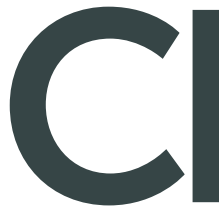

\section{Accepted Manuscript}

This article can be cited before page numbers have been issued, to do this please use: H. Li, W. Zhao, W. Dai, J. Long, M. Watanabe, S. Meier, S. Saravanamurugan, S. Yang and A. Riisager, Green Chem., 2018,
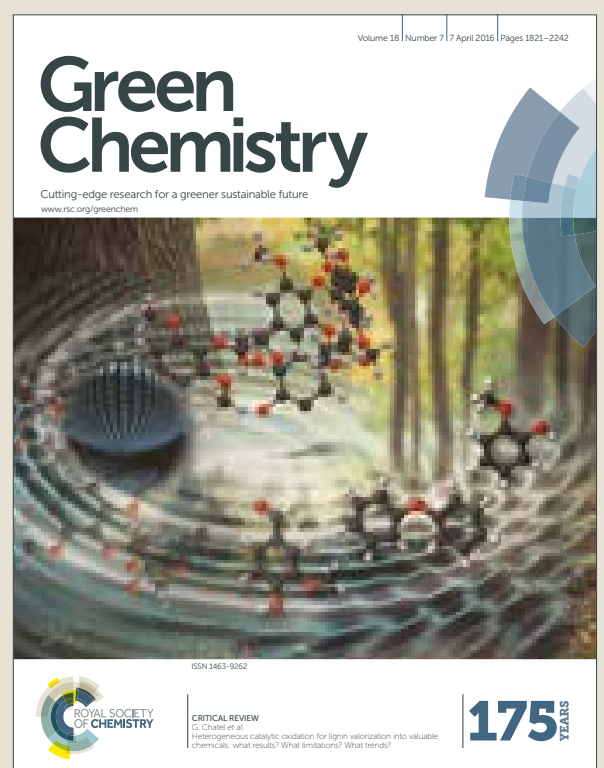

175
This is an Accepted Manuscript, which has been through the Royal Society of Chemistry peer review process and has been accepted for publication.

Accepted Manuscripts are published online shortly after acceptance, before technical editing, formatting and proof reading. Using this free service, authors can make their results available to the community, in citable form, before we publish the edited article. We will replace this Accepted Manuscript with the edited and formatted Advance Article as soon as it is available.

You can find more information about Accepted Manuscripts in the author guidelines.

Please note that technical editing may introduce minor changes to the text and/or graphics, which may alter content. The journal's standard Terms \& Conditions and the ethical guidelines, outlined in our author and reviewer resource centre, still apply. In no event shall the Royal Society of Chemistry be held responsible for any errors or omissions in this Accepted Manuscript or any consequences arising from the use of any information it contains. 


\section{Journal Name}

\section{PAPER}

\section{Noble metal-free upgrading of multi-unsaturated biomass derivatives at room temperature: Silyl species enable reactivity}

Received 00th January 20xx, Accepted 00th January 20xx DOI: $10.1039 / x 0 \times x 00000 x$

www.rsc.org/

\author{
Hu Li ${ }^{a}$, Wenfeng Zhao ${ }^{a}$, Wenshuai Dai ${ }^{b}$, Jingxuan Long ${ }^{a}$, Masaru Watanabe ${ }^{c}$, Sebastian Meier ${ }^{d *}$, \\ Shunmugavel Saravanamurugan ${ }^{* *}$, Song Yang ${ }^{a *}$, Anders Riisager ${ }^{d}$
}

\section{Introduction}

Catalytic hydrogenation of unsaturated carbon-containing bonds ( $\mathrm{C}=\mathrm{C}, \mathrm{C}=\mathrm{N}, \mathrm{C}=\mathrm{O}$ ) in organic compounds with metal complexes or particles is a prolific approach that is extensively applied in petroleum, pharmaceutical, fine chemical, perfume and flavoring industries 1 . Noble (e.g., $\mathrm{Au}, \mathrm{Pt}, \mathrm{Ru}, \mathrm{Rh}$ ) and transition (e.g., $\mathrm{Fe}, \mathrm{Co}, \mathrm{Ni}, \mathrm{Cu}$ ) metals prevail in both heterogeneous and homogeneous catalytic hydrogenation processes as catalysts with favourable activity and selectivity ${ }^{2}$. The co-use of unique organic/inorganic ligands, suitable acidic species, or additional metallic additives with relatively harsh reaction conditions is a prerequisite to ensure good reactivity in the hydrogenation process, which on the other hand may lead to accelerated catalyst deactivation ${ }^{3}$.

\footnotetext{
a State Key Laboratory Breeding Base of Green Pesticide \& Agricultural Bioengineering, Key Laboratory of Green Pesticide \& Agricultural Bioengineering, Ministry of Education, State-Local Joint Engineering Lab for Comprehensive Utilization of Biomass, Center for R\&D of Fine Chemicals, Guizhou University, Guiyang, Guizhou 550025, China; Email: jhzx.msm@gmail.com (SY)

${ }^{b}$ Beijing National Laboratory of Molecular Science, State Key Laboratory of Molecular Reaction Dynamics, Institute of Chemistry, Chinese Academy of Sciences; University of Chinese Academy of Sciences, Beijing 100049, China ${ }^{c}$ Research Center of Supercritical Fluid Technology, Graduate School of Engineering, Tohoku University, 6-6-11, Aoba, Aramaki, Aoba-ku, Sendai 9808579, Japan

${ }^{d}$ Department of Chemistry, Technical University of Denmark, DK-2800 Kgs. Lyngby, Denmark; Email: semei@kemi.dtu.dk (SM)

e Laboratory of Bioproduct Chemistry, Center of Innovative and Applied Bioprocessing (CIAB), Mohali 140 306, Punjab, India; Email: saravana@ciab.res.in (SS)

Electronic Supplementary Information (ESI) available:

See DOI: $10.1039 / x 0 x x 00000 x$
}

Currently, much attention is being paid to the selective hydrogenation of unsaturated functionalities. For example, partial or complete reduction of oxygenates to alcohols or alkanes 4, regioselective reduction of polyols or polyenes ${ }^{5}$, and selective hydrogenation of $\alpha, 6$-unsaturated carbonyl compounds ${ }^{6}$ can be achieved using well-designed metal catalysts. Given the significance of selectivity in reduction reactions, it would be especially attractive to control the hydrogenation capability toward multi-unsaturated functional groups with similar redox potential. As the most abundant organic carbon source derived from photosynthesis, lignocellulosic biomass has been explored as promising renewable feedstock for producing a wide range of platform molecules that can compete with petroleum-based products ${ }^{7}$. One of the bottlenecks for the efficient upgrade of biomass is the selective hydrogenation of oxygenated species that are rich in downstream derivatives such as sugar, organic acid, aromatic and furanic carbonyl compounds ${ }^{8}$, especially those concurrently containing two or more different types of carbonyl groups. Levulinic acid (LA) and its esters are a class of biomass-derived dicarbonyl compounds ${ }^{9}$, which can be selectively hydrogenated to value-added products, especially $\gamma$-valerolactone (GVL) and 1,4pentanediol (1,4-PD) over metal catalysts ${ }^{10}$. Significant progress has been achieved with metal-mediated biomass valorisation processes in the presence of excessive hydrogen donors along with high pressure and reaction temperature (Table S1), while the development of more benign and cost-effective catalytic systems would be desirable.

In most cases, precious or transition metal species coupled with suitable additives were reported to be efficient catalysts for the hydrogenation reactions ${ }^{11}$. Due to significantly enhanced sustainability, alkali carbonates, which are low-cost, pollution-free and obtainable from $\mathrm{CO}_{2}{ }^{12}$, seem better candidates for the 
hydrogenation reactions. In the present study, we present a sustainable carbonate-based catalytic process (Fig. 1) that is able to selectively hydrogenate dicarbonyl compounds and tolerate other unsaturated moieties by using environmentally benign, cheap, and air-stable hydrosilanes ${ }^{13}$ as hydride source. The silyl ether species formed in situ in the hydrogenation process enable the control of selectivity in the reduction of multi-unsaturated carbonyl compounds that bear aldehyde/ketone, ester/amide, and aromatic/furanic groups.

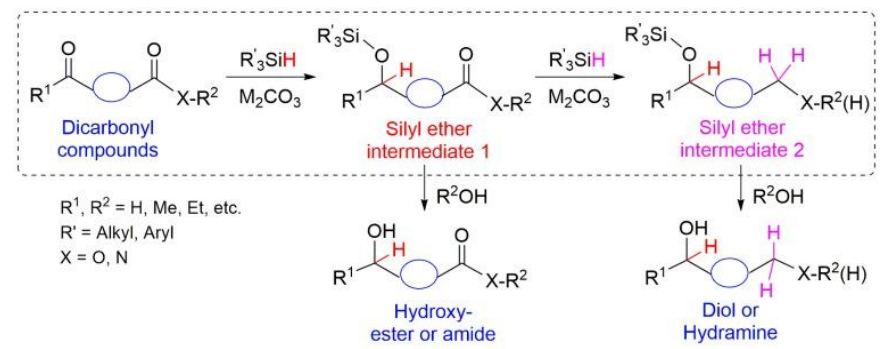

Fig. 1. Selective hydrogenation of dicarbonyl compounds to hydroxy-ester/amide or diol/hydramine catalysed by alkali carbonates $\left(\mathrm{M}_{2} \mathrm{CO}_{3}\right)$.

\section{Results and discussion}

\section{Controllable hydrogenation of bio-based ethyl levulinate}

Initial screening studies were conducted to investigate the selective hydrogenation of ethyl levulinate (EL) to GVL or 1,4-PD over $\mathrm{Cs}_{2} \mathrm{CO}_{3}$ using triethoxysilane $(\mathrm{EtO})_{3} \mathrm{SiH}$ as reducing agent in the biomassderived solvent 2-methyltetrahydrofuran (MTHF), and the results are collected in Table 1. At room temperature $\left(25^{\circ} \mathrm{C}\right)$ in the presence of $\mathrm{Cs}_{2} \mathrm{CO}_{3}$ and 1.5 equiv. $\mathrm{H}^{-}, 74 \%$ yield of $\mathrm{GVL}$ could be achieved from $\mathrm{EL}$ in $0.5 \mathrm{~h}$, while the silyl ether Si-1 (21\%) was found to be the dominant byproduct (Table S2, entry 1 ). After post-treatment with ethanol under stirring at $25 \stackrel{\circ}{\circ}$ for $2 \mathrm{~h}$, the GVL yield increased to $87 \%$ by partial consumption of Si-1 (10\% yield; Table S2, entry 2). Upon further increase of the post-treatment temperature to $80 \stackrel{\circ}{ }$, a high GVL yield of $98 \%$ was obtained with a TOF value of $39.2 \mathrm{~h}^{-1}$ (Table 1, entry 1), giving tetraethyl orthosilicate $\left[\mathrm{Si}(\mathrm{OEt})_{4}\right]$ as the co-product (Figs. S1 and S2).

In addition to $\mathrm{Cs}_{2} \mathrm{CO}_{3}$, other alkali carbonates including $\mathrm{K}_{2} \mathrm{CO}_{3}$, $\mathrm{Na}_{2} \mathrm{CO}_{3}$, and $\mathrm{Li}_{2} \mathrm{CO}_{3}$ were examined and proved almost inactive for the hydrogenation of EL with no more than $2 \%$ conversion (Table S2, entries 3-5). This finding seems to imply a positive role of cesium in the hydrogenation process. However, the inactivity of $\mathrm{CsCl}, \mathrm{CsNO}_{3}$ and $\mathrm{CsOOCH}$ (Table S2, entries 6-8) is contradictory to the speculation, which on the other hand indicates the activation effect of the carbonate. The co-addition of 18-crown-6 (10 mol\%) significantly enhanced the performance of $\mathrm{K}_{2} \mathrm{CO}_{3}$ for the reaction (Table $\mathrm{S} 2$, entry 9) by increasing its solubility, clearly proving the dominant role of carbonate in the catalytic process. Although $\mathrm{CsOH}$ showed comparable activity to $\mathrm{Cs}_{2} \mathrm{CO}_{3}$ in terms of $\mathrm{EL}$ conversion, the selectivity toward GVL significantly dropped to $82 \%$ with 1,4 pentanediol (1,4-PD) as the primary byproduct ( $13 \%$ yield; Table 1 , entry 2). This result further indicates that the appropriate nucleophilicity of the dissociative carbonate is crucial for the pronounced reactivity in the selective hydrogenation of the dicarbonyl compound. In line with this finding, the type of solvent was illustrated to significantly influence the reactivity (Fig. S3), where MTHF is capable of dispersing $\mathrm{Cs}_{2} \mathrm{CO}_{3}$ and $(\mathrm{EtO})_{3} \mathrm{SiH}$ to enable their contact with the substrate EL. In contrast, more polar solvent (DMSO and acetonitrile) was not able to completely convert EL (Fig. S3), while less polar solvent ( $n$-hexane) promoted the over-hydrogenation of GVL to afford corresponding acetal and 1,4-PD (Figs. S4 and S5). In the case of using tetrahydrofuran (THF) as the solvent with a structure quite similar to that of MTHF, GVL was found to be the predominant product after post-treatment at variable temperatures (Fig. S6), while GVL-derived acetals (2-ethoxy-5-methyltetrahydrofuran and triethyl (5-methyltetrahydrofuran-2-yl) silicate) without 1,4-PD and MTHF were detected by GC-MS (Fig. S7).

Both the type and dosage of hydrosilanes were found to directly affect both EL conversion and selectivity towards GVL or 1,4-PD. Among the tested hydrosilanes, $(\mathrm{EtO})_{3} \mathrm{SiH}$ exhibited the highest activity in the synthesis of GVL from EL, while the other hydrosilanes were either too active (with ca. 9\% yield of 1,4-PD formed in the presence of $\mathrm{PhSiH}_{3}$ ) or inert (e.g., $\mathrm{Et}_{3} \mathrm{SiH}$ and $\mathrm{Ph}_{2} \mathrm{SiH}_{2}$ ) for the reaction (Table S3). 1.5 equiv. $\mathrm{H}^{-}$of $(\mathrm{EtO})_{3} \mathrm{SiH}$ was most favorable for the formation of GVL (Fig. S8), while the use of larger excess of hydrosilane (2.5-5.5 equiv. $\mathrm{H}^{-}$) resulted in reduction of the ester group in either EL or GVL (Fig. S1), giving 1,4-PD as the major co-product in up to ca. $10 \%$ yield. Owing to its relatively low nucleophilicity, $\mathrm{Cs}_{2} \mathrm{CO}_{3}$ showed inferior activity relative to $\mathrm{CsOH}$ in the formation of 1,4-PD (yield: 4\% vs 38\%; Table 1, entries 3 and 4). However, a low carbon balance was observed in the latter case $(89 \%)$, which could be ascribed to the presence of strongly basic $\mathrm{OH}^{-}$causing undesired side reactions like condensation or the formation of stable intermediates such as 2-ethoxy-5-methyltetrahydrofuran (Fig. S9). It should be noted that an increased $1,4-\mathrm{PD}$ yield of $71 \%$ with $21 \% \mathrm{GVL}$ could be obtained with $\mathrm{Cs}_{2} \mathrm{CO}_{3}$ and 3.5 equiv. $\mathrm{H}^{-}$of $(\mathrm{EtO})_{3} \mathrm{SiH}$ by prolonging the reaction time to $6 \mathrm{~h}$ (Fig. S10). When the more active phenylsilane $\left(\mathrm{PhSiH}_{3}\right)$ was used as a reducing agent in the presence of $\mathrm{Cs}_{2} \mathrm{CO}_{3}$, a $25 \%$ yield of 1,4PD was obtained after $0.5 \mathrm{~h}$, which is comparable to the yield (20\%) achieved with (EtO) ${ }_{3} \mathrm{SiH}$ after $2 \mathrm{~h}$ under otherwise identical conditions (Table 1, entries 5 and 6 ). With an extension of the reaction time to 6 $h$, an unprecedented high yield of 1,4-PD (95\%) was attained using $\mathrm{Cs}_{2} \mathrm{CO}_{3}$ and $\mathrm{PhSiH}_{3}$ (Table 1, entry 7). Although a slight increase of

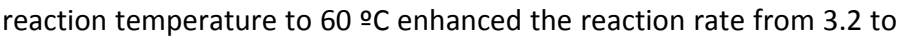
$6.9 \mathrm{~h}^{-1}$, the 1,4-PD yield together with the carbon balance was markedly reduced to ca. $87 \%$ (Table 1 , entry 8 ), due to the formation of some unidentified products. These results demonstrate that room temperature $(25 \stackrel{\circ}{\circ}$ ) was preferable to warrant high carbon balance through the reaction process, while the dosage and type of hydrosilane as well as the reaction time, were key factors determining the selectivity and product distribution.

For comparison, some previously reported results using metalbased catalysts for the production of GVL and 1,4-PD are listed in Table 1, entries 9-12 ${ }^{14}$. The $\mathrm{Pt} / \mathrm{V}_{2} \mathrm{O}_{5}$ catalyst could afford a yield of GVL (99\%) comparable to our catalytic system (entry 9 vs entry 1 ), but 


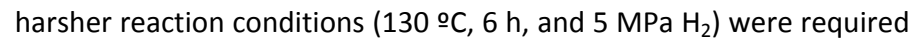
and the reaction rate was much lower (TOF: $16.5 \mathrm{~h}^{-1}$ with $\mathrm{Pt} / \mathrm{V}_{2} \mathrm{O}_{5}$ vs $39.2 \mathrm{~h}^{-1}$ with $\mathrm{Cs}_{2} \mathrm{CO}_{3}$ at 25 o $\mathrm{C}$ ). Even higher reaction temperature (160 oC), longer reaction time (10-24 h), or higher $\mathrm{H}_{2}$ pressure (3-5 MPa) was required over metallic catalysts to produce 1,2-PD with yields of 48-93\% and TOF values of 0.1-1.9 $\mathrm{h}^{-1}$ (entries 10-12). It is also worth noting that the metal catalysts with serious leaching and toxicity issues are prone to cause the formation of cyclic ether or monoalcohol. For example, MTHF (19\%), 2-pentanol (20\%), and 1-pentanol (6\%) were found to be the major byproducts using $\mathrm{Pt}-\mathrm{Mo} / \mathrm{SiO}_{2}$ (39), thus greatly annihilating the selectivity toward 1,4-PD (48\%; entry 11). In contrast, our catalytic system was able to selectively produce 1,4PD in a higher yield of $95 \%$ with TOF of $3.2 \mathrm{~h}^{-1}$ (entry 7) by simply increasing the hydrosilane dosage from 1.5 to 3.5 equiv. of $\mathrm{H}^{-}$. This finding manifests the advantages of the $\mathrm{Cs}_{2} \mathrm{CO}_{3}$-promoted hydrosilylation process in the selective hydrogenation of $\mathrm{EL}, \mathrm{a}$ dicarbonyl compound, into GVL or 1,4-PD at room temperature.

Interestingly, when LA instead of EL was used as substrate, a good GVL yield of $93 \%$ (Table 1, entry 13 ) was also obtained under the optimal reaction conditions, indicating that the developed catalytic system can be potentially used for the reduction of biomass-derived organic acids. As one of the promising silanes used for hydrogenation, polymethylhydrosiloxane (PMHS) is a polymeric byproduct of the silicone industry, which is non-toxic, inexpensive, safe, and water/air insensitive ${ }^{15}$. Although a low GVL yield (25\%) was obtained using PMHS after a short reaction time of $0.5 \mathrm{~h}$ (Table S3), the yield could be improved to ca. $90 \%$ over our developed catalytic system by prolonging the reaction time to $2 \mathrm{~h}$ (Table 1 , entry 14). In order to examine the feasibility of the developed catalytic system in practical production, the reaction was scaled up from 2 to $50 \mathrm{~mL}$, and the amount of EL was accordingly increased from $144 \mathrm{mg}$ to $3.6 \mathrm{~g}$. Although the substrate was scaled up from milligram to gram by 25 fold, GVL and 1,4-PD could be obtained in good yields of 90 and $82 \%$ with 5 mol\% $\mathrm{Cs}_{2} \mathrm{CO}_{3}$ at $25 \stackrel{\circ}{\circ}$ using 1.5 equiv. $\mathrm{H}^{-}$of $(\mathrm{EtO})_{3} \mathrm{SiH}$ and 3.5 equiv. $\mathrm{H}^{-}$of $\mathrm{PhSiH}_{3}$ after $1 \mathrm{~h}$ and $8 \mathrm{~h}$, respectively. These results demonstrate the great potential of the $\mathrm{Cs}_{2} \mathrm{CO}_{3}$-hydrosilane catalytic system for industrial application.

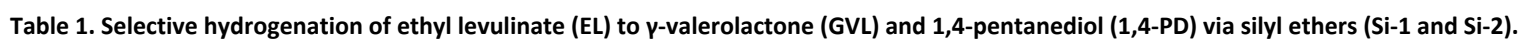

\begin{tabular}{|c|c|c|c|c|c|c|c|c|c|c|c|c|}
\hline \multirow{3}{*}{ Entry } & \multirow{3}{*}{ Catalyst } & O & $\begin{array}{r}1[\mathrm{H}] \\
(\mathrm{EtO})_{3} \\
\mathrm{Cs}_{2} \mathrm{CC}\end{array}$ & \multicolumn{3}{|c|}{ 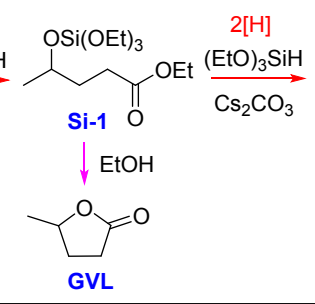 } & \multicolumn{3}{|c|}{$\underbrace{\mathrm{Si}-2}_{1,4-\mathrm{PD}} \mathrm{OSi}$} & \multirow{3}{*}{\multicolumn{2}{|c|}{$\begin{array}{l}\mathrm{CB}^{a} \\
(\%)\end{array}$}} & \multirow{3}{*}{$\begin{array}{c}\text { TOF }^{b} \\
\left(\mathrm{~h}^{-1}\right)\end{array}$} \\
\hline & & \multicolumn{2}{|c|}{ Hydrogen-donor } & \multirow{2}{*}{$\begin{array}{l}\text { Temp } \\
\text { (으) }\end{array}$} & \multirow{2}{*}{$\begin{array}{c}\text { Time } \\
\text { (h) } \\
\end{array}$} & \multirow{2}{*}{$\begin{array}{c}\text { EL conv. } \\
(\%)\end{array}$} & \multicolumn{3}{|c|}{ Product yield (\%) } & & & \\
\hline & & Type & $\mathrm{H}^{-}$dosage & & & & Si-1 & GVL & Si-2 & & & \\
\hline 1 & $\mathrm{Cs}_{2} \mathrm{CO}_{3}$ & $(\mathrm{EtO})_{3} \mathrm{SiH}$ & 1.5 equiv. & 25 & 0.5 & $>99$ & $<1$ & 98 & $<1$ & 0 & 99 & 39.2 \\
\hline 2 & $\mathrm{CsOH}$ & $(\mathrm{EtO})_{3} \mathrm{SiH}$ & 1.5 equiv. & 25 & 0.5 & 100 & 0 & 82 & 2 & 13 & 97 & 32.8 \\
\hline 3 & $\mathrm{Cs}_{2} \mathrm{CO}_{3}$ & $(\mathrm{EtO})_{3} \mathrm{SiH}$ & 3.5 equiv. & 25 & 0.5 & 100 & 0 & 92 & 3 & 4 & 99 & 36.8 \\
\hline 4 & $\mathrm{CsOH}$ & $(\mathrm{EtO})_{3} \mathrm{SiH}$ & 3.5 equiv. & 25 & 0.5 & 100 & 0 & 51 & $<1$ & 38 & 89 & 20.4 \\
\hline 5 & $\mathrm{Cs}_{2} \mathrm{CO}_{3}$ & $(\mathrm{EtO})_{3} \mathrm{SiH}$ & 3.5 equiv. & 25 & 2 & 100 & 0 & 77 & 1 & 20 & 98 & 7.7 \\
\hline 6 & $\mathrm{Cs}_{2} \mathrm{CO}_{3}$ & $\mathrm{PhSiH}_{3}$ & 3.5 equiv. & 25 & 0.5 & 99 & $<1$ & 72 & 1 & 25 & $>99$ & 28.8 \\
\hline 7 & $\mathrm{Cs}_{2} \mathrm{CO}_{3}$ & $\mathrm{PhSiH}_{3}$ & 3.5 equiv. & 25 & 6 & 100 & 0 & 2 & $<1$ & 95 & 97 & 3.2 \\
\hline 8 & $\mathrm{Cs}_{2} \mathrm{CO}_{3}$ & $\mathrm{PhSiH}_{3}$ & 3.5 equiv. & 60 & 2.5 & 100 & 0 & $<1$ & 0 & 87 & 87 & 6.9 \\
\hline $9^{c}$ & $\mathrm{Pt} / \mathrm{V}_{2} \mathrm{O}_{5}$ & $5 \mathrm{MPa} \mathrm{H}_{2}$ & - & 130 & 6 & $>99$ & - & 99 & - & 1 & 100 & 16.5 \\
\hline $10^{c}$ & Pt-Mo/HAP & $3 \mathrm{MPa} \mathrm{H}_{2}$ & - & 130 & 24 & $>99$ & - & $<1$ & - & 93 & 94 & 1.9 \\
\hline $11^{d}$ & $\mathrm{Pt}-\mathrm{Mo} / \mathrm{SiO}_{2}$ & $5 \mathrm{MPa} \mathrm{H}_{2}$ & - & 130 & 24 & $>99$ & - & 0 & - & 48 & 93 & 1.0 \\
\hline $12^{e}$ & CuAIZn & $4 \mathrm{MPa} \mathrm{H}_{2}$ & - & 160 & 10 & 100 & - & 17 & - & 82.9 & 99.9 & 0.1 \\
\hline $13^{f}$ & $\mathrm{Cs}_{2} \mathrm{CO}_{3}$ & $(\mathrm{EtO})_{3} \mathrm{SiH}$ & 1.5 equiv. & 25 & 0.5 & 95 & 0 & 93 & $<1$ & 0 & 98 & 37.2 \\
\hline $14^{g}$ & $\mathrm{Cs}_{2} \mathrm{CO}_{3}$ & PMHS & 1.5 equiv. & 25 & 2 & 96 & $<1$ & 90 & $<1$ & 2 & 97 & 9.0 \\
\hline
\end{tabular}

Reaction conditions: $1 \mathrm{mmol} \mathrm{EL}, 1.5$ or 3.5 equiv. $\mathrm{H}^{-}, 5 \mathrm{~mol} \%$ catalyst, $2 \mathrm{~mL} \mathrm{MTHF}$; After the reaction, $2 \mathrm{~mL}$ ethanol was added into the reaction mixture and stirred at 80 ㅇ for 2 h. ${ }^{a}$ CB: Carbon balance; ${ }^{b}$ TOF (turnover frequency) is defined as (mole of primary product) / (mole of active species $\times$ time); ${ }^{c}$ Ref. (14a); ${ }^{d}$ Ref. (14b); ${ }^{e}$ Ref. (14b); ${ }^{f}$ LA instead of EL was used as substrate; ${ }^{g}$ Polymethylhydrosiloxane (PMHS) was used as reducing agent. 


\section{ARTICLE}

\section{NMR study of reaction pathways}

To elucidate the reaction pathways, in situ NMR studies were conducted to monitor the product distribution during the reduction process of EL to $\mathrm{GVL}$ in the presence of $\mathrm{Cs}_{2} \mathrm{CO}_{3}$ with $(\mathrm{EtO})_{3} \mathrm{SiH}$. The in situ ${ }^{13} \mathrm{C}$ NMR spectra of the EL hydrogenation (Fig. 2A) display that the silyl ether (Si-1) and ethyl 4-hydroxypentanoate (EHP) are possibly key intermediates to the final product GVL. EL was almost completely converted in $0.5 \mathrm{~h}$ even without magnetic stirring, where Si-1 was observed as the first intermediate, followed by gradual degradation to EHP (Fig. S11). On the other hand, the absence of signals in the olefinic region in the in situ ${ }^{13} \mathrm{C}$ NMR spectra of the reaction mixture (Fig. 2B) validates the initial occurrence of the hydrogenation step, rather than a possible initial cyclization of EL to form $\alpha$-angelica lactone (Fig. 3). After reacting for different intervals (3-60 min), the characteristic regions belonging to EHP and GVL in ex situ NMR spectra of the reaction mixture quenched by methanol were recorded (Fig. S12). Clearly, better selectivity toward GVL was observed after methanol treatment, as compared with the in situ obtained results (Fig. 2A) in the NMR tube. This finding verifies the importance of the post-treatment process (e.g., with ethanol) at the specific temperature (ca. $80^{\circ} \mathrm{C}$ ) to accomplish the following cyclization step, thus exclusively giving GVL.

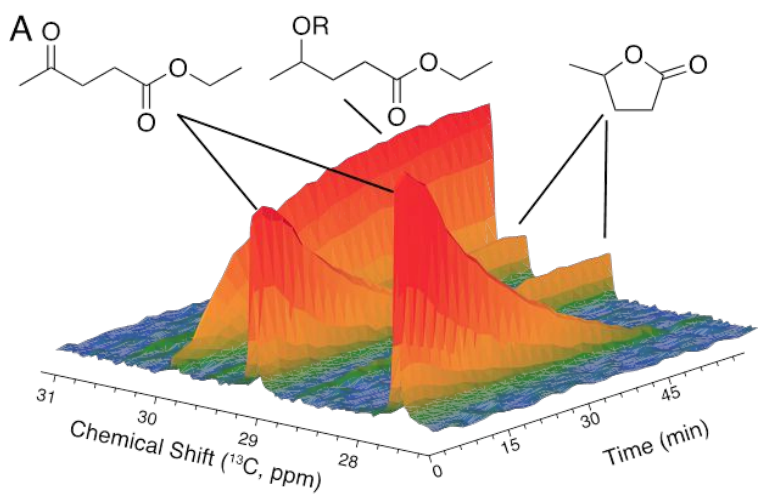

B olefinic spectral region

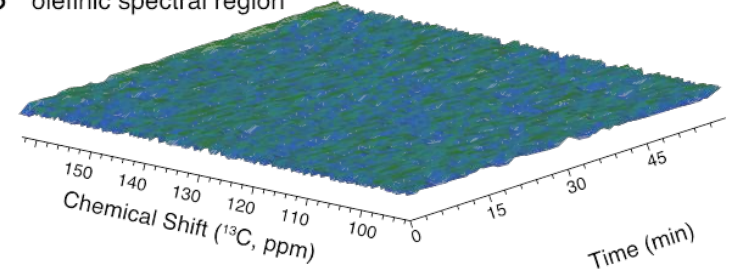

Fig. 2. In situ ${ }^{13} \mathrm{C}$ NMR spectra for the hydrogenation of ethyl levulinate (EL). (A) Formation of $\gamma$-valerolactone (GVL) via the silyl ether (Si-1) and ethyl 4hydroxypentanoate (EHP); (B) Olefinic region in ${ }^{13} \mathrm{C}$ NMR spectra of the reaction mixture. Reaction conditions: $1 \mathrm{mmol} \mathrm{EL}, 1.5$ equiv. $\mathrm{H}^{-}$of $(\mathrm{EtO})_{3} \mathrm{SiH}, 5 \mathrm{~mol} \% \mathrm{Cs}_{2} \mathrm{CO}_{3}$, $2 \mathrm{~mL}$ MTHF, $25 \stackrel{\circ}{ }{ }^{\circ}$.

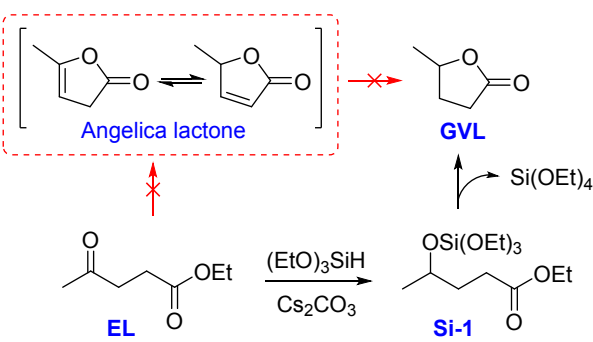

Fig. 3. Reaction pathway for EL-to-GVL conversion

The simultaneous presence of the intermediates EHP and Si-1 in the reaction mixture can also be distinguished by the ${ }^{1} \mathrm{H}-{ }^{13} \mathrm{C}$ HMBC spectra of the reaction mixture (Fig. $4 \mathrm{~A}$ ). The $\mathrm{Si}$ attachment in Si-1 can be affirmed by ${ }^{1} \mathrm{H}-{ }^{29} \mathrm{Si} \mathrm{HMBC}$ (Fig. 4A). To some extent, the stable intermediates are not favorable for directly producing GVL from EL, due to the requirement of secondary post-treatment. Fortunately, the reaction rate is significantly enhanced after a specific period (ca. 15$30 \mathrm{~min}$ ) of the steady reaction process, as shown in Fig. 4B. The formation of the intermediates as well as the siloxane $\mathrm{Si}(\mathrm{OEt})_{4}$ is most likely to promote the dissolution of the catalytically active species (carbonate), thus leading to rapid or runaway reaction. Furthermore, the incorporation of hydride from the hydrosilane into the substrate EL can be illustrated by comparison of the obtained ${ }^{1} \mathrm{H}$ NMR spectra (Fig. S13) using normal $\mathrm{Ph}_{2} \mathrm{SiH}_{2}$ and deuterium-labeled $\mathrm{Ph}_{2} \mathrm{SiD}_{2}$ as reducing agents. Kinetic isotope effect (KIE) study disclosed a significant difference in $k_{\mathrm{H}} / k_{\mathrm{D}}$ value (ca. 2.4) when the hydride was supplied either by $\mathrm{Ph}_{2} \mathrm{SiH}_{2}$ or $\mathrm{Ph}_{2} \mathrm{SiD}_{2}$, further supporting that the relative activity of the employed hydrosilane plays a key role in the selective hydrogenation. On the other hand, ${ }^{1} \mathrm{H}-{ }^{13} \mathrm{C}$ HSQC NMR spectra of the reaction mixture after post-treatment with methanol- $\mathrm{d}_{4}$ at $60 \stackrel{\circ}{\circ}$ for $2 \mathrm{~h}$ demonstrated the complete conversion of the intermediates into GVL (Fig. S14), which is in agreement with the corresponding ${ }^{13} \mathrm{C}$ NMR spectra (Figs. S15 and S16). 


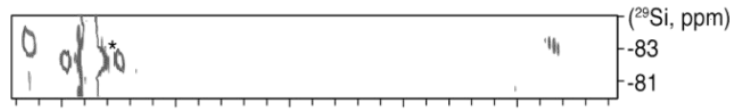

A

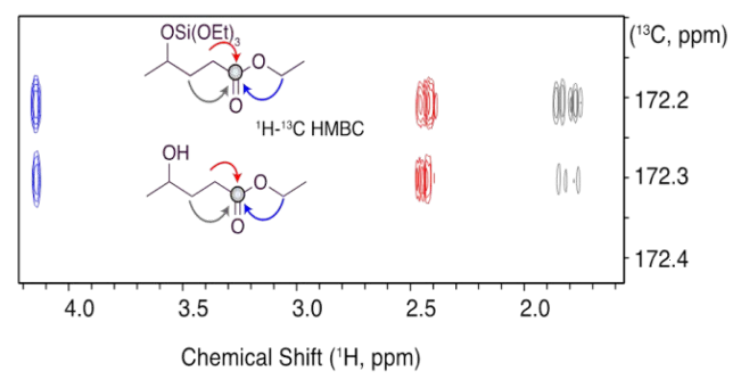

B

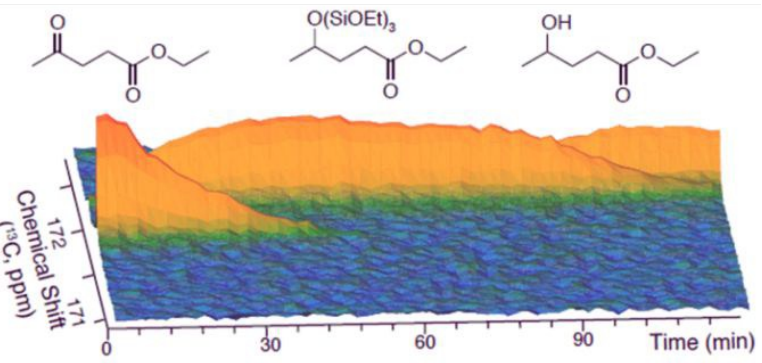

Fig. 4. In situ NMR spectra of the reaction mixture for ethyl levulinate (EL) conversion. (A) In situ ${ }^{1} \mathrm{H}-{ }^{13} \mathrm{C} /{ }^{29} \mathrm{Si} \mathrm{HMBC}$ spectra of the intermediates [ethyl 4hydroxypentanoate (EHP) and silyl ether (Si-1)], and (B) In situ time-series of ${ }^{13} \mathrm{C}$ NMR spectra for the hydrogenation of ethyl levulinate (EL) to the intermediates [silyl ether (Si-1) and ethyl 4-hydroxypentanoate (EHP)]; Tetraethyl orthosilicate is the asterisk in ${ }^{1} \mathrm{H}-{ }^{29} \mathrm{Si} \mathrm{HMBC}$ spectrum (top).

\section{Upgrade of carbonate}

Although the used catalyst $\mathrm{Cs}_{2} \mathrm{CO}_{3}$ is cheap, widely available and eco-friendly, attempts were made to investigate its recoverability for potential recycling or further upgrading. Initially, the effect of $\mathrm{Cs}_{2} \mathrm{CO}_{3}$ dosage on the conversion of EL to GVL was studied, where no more than $80 \%$ yields of GVL were obtained using less than 5 mol\% $\mathrm{Cs}_{2} \mathrm{CO}_{3}$ (Fig. S17). This relatively low yield shows the importance of using sufficient $\mathrm{Cs}_{2} \mathrm{CO}_{3}$ (5 mol\%) for good catalytic performance. However, the amount of $\mathrm{Cs}_{2} \mathrm{CO}_{3}$ (separated out by centrifugation) was decreased by around $68 \%$ after the first cycle of the reaction. Notably, the recovered solids were characterized by STEM (Fig. S18) to be $\mathrm{Cs}_{2} \mathrm{CO}_{3}$ with additional silicon compounds, thus underlining the difficulty in completely recycling the catalyst. TEM images of both fresh and recovered $\mathrm{CS}_{2} \mathrm{CO}_{3}$ pre-dispersed into THF indicated the formation of nano-sized particles (Fig. S19), which is in agreement with the superior catalytic results of the alkali carbonate salts being more soluble (Table S2, entries 1-5). Instead, the addition of ethanol $(2 \mathrm{~mL})$ into the liquid mixture after the reaction led to full conversion of the residual carbonate in both solid and leached states into formate (>95\% yields) in $2 \mathrm{~h}$ (Fig. S20), which was confirmed by ${ }^{1} \mathrm{H}$ NMR through detection of a singlet with a chemical shift of about 8.6 ppm belonging to ${ }^{1} \mathrm{HCOO}$ - (Fig. S21). Therefore, it would be more preferable to co-synthesize the expected products together with the value-added formate by post-treatment with ethanol.

\section{Selective hydrogenation of dicarbonyl compounds to hydroxy esters and diols}

Cyclic ether or mono-alcohol is typically formed in the synthesis of diols from dicarbonyl compounds ${ }^{14 b, 16}$. To examine the versatility of the catalytic system developed in this study, the substrate scope was further expanded to other dicarbonyl compounds (Table 2). Both diketones and dialdehydes could be selectively reduced to diols with yields of $87-95 \%$ in $0.5-1 \mathrm{~h}$ (entries $1-3$ ). The exclusive selectivity toward the diols further indicates the intact $\mathrm{C}-\mathrm{O}$ bond during the processes of reduction and post-treatment, which is unambiguously attributed to the formation of silyl ether under the mild reaction conditions. Apart from the aromatic ring, the nitro group was also intact during the hydrogenation process (entry 4). This makes the catalytic system capable of exclusively producing alcohols with good compatibility to other multi-unsaturated functional groups. By prolonging the reaction time to $6 \mathrm{~h}$ and increasing hydrosilane dosage to 2.5 equiv. $\mathrm{H}^{-}$of $\mathrm{PhSiH}_{3}$, methyl benzoate and methyl $p$-methyl benzoate could be hydrogenated to benzyl alcohol ( $96 \%$ yield, entry 5) and $p$-methylbenzyl alcohol (>99\% yield, entry 6$)$, respectively. In the presence of both aldehyde/ketone and ester, the selective reduction of aldehyde or ketone to alcohol without affecting the ester group could be achieved (entries 7, 9 and 11). Importantly, both the presented carboxides could be reduced to diols in high yields of $88-96 \%$ from those dicarbonyl compounds containing aldehyde/ketone and ester groups (entries 8, 10 and 12).

Table 2. Selective reduction of carbonyl compounds bearing multi-unsaturated groups to alcohols via silyl ethers.

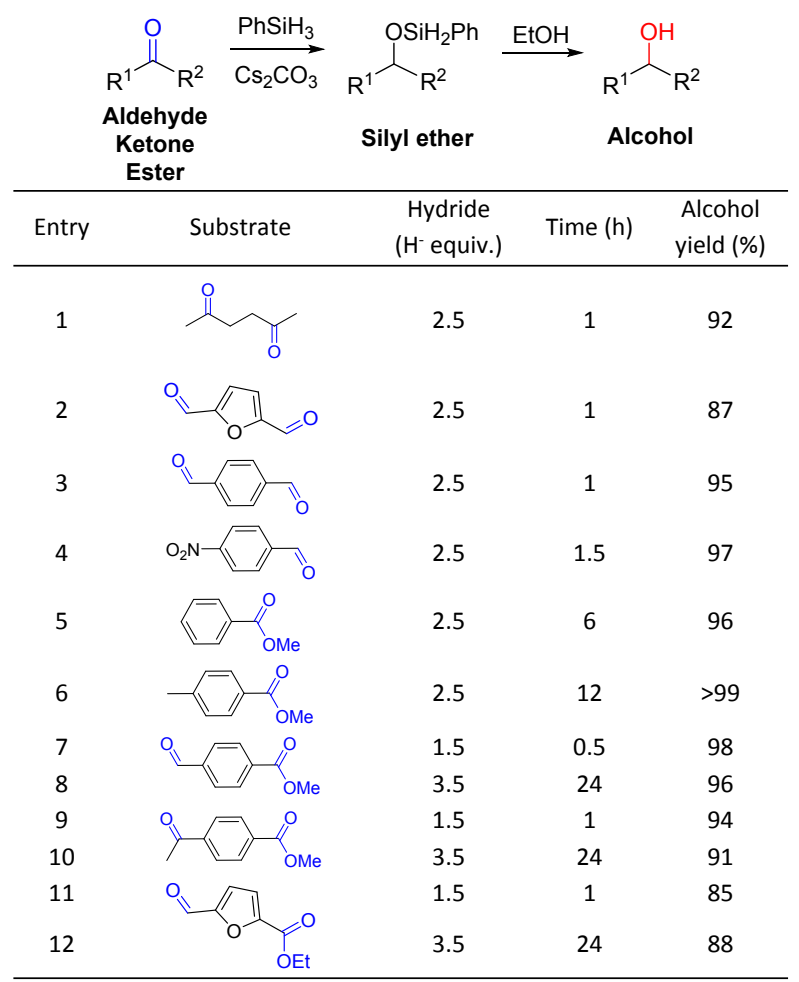


Reaction conditions: 1 mmol substrate, 1.5 -3.5 equiv. $\mathrm{H}^{-}$of $\mathrm{PhSiH}_{3}, 5 \mathrm{~mol} \% \mathrm{Cs}_{2} \mathrm{CO}_{3}, 2$ $\mathrm{mL}$ MTHF, 25 o $\mathrm{C}$; After the reaction, $2 \mathrm{~mL}$ ethanol was added to the liquid mixture and stirred at $80 \stackrel{\circ}{\circ}$ for $2 \mathrm{~h}$.

\section{Selective hydrogenation of multi-unsaturated amides}

Pyrrolidones are a class of amides extensively applied as solvents and feedstocks for fibers or surfactants ${ }^{17}$. In the present study, starting from levulinic acid (LA) and amines, a variety of $N$-substituted lactams (i.e., pyrrolidones) could be synthesized in good yields of 85 $92 \%$ at $120{ }^{\circ} \mathrm{C}$ using formic acid both as an acid and as hydrogen source in the absence of a catalyst (Table S4). The results are comparable to those obtained over metal catalysts such as Ir and $\mathrm{Ni}$ in the production of lactams ${ }^{17,18}$. In general, the controllable reduction of lactams is one of the promising ways to produce cyclamines. However, the cleavage of $\mathrm{C}-\mathrm{N}$ bonds often occurs over metal (e.g., Ru, $\mathrm{Mn}$, and $\mathrm{Fe}$ ) catalysts during the hydrogenation process, simultaneously giving amines and alcohols as products ${ }^{19}$. Typically, the lactam is more inert towards reduction compared with the ester analogue ${ }^{11 e}$, while extension of the reaction time to $24-36 \mathrm{~h}$ could yield $81-99 \%$ cyclamine with selectivity of $95-100 \%$ in the presence of the hydrosilane $/ \mathrm{Cs}_{2} \mathrm{CO}_{3}$ catalytic system at room temperature (Table 3). Notably, this catalytic system is compatible with aliphatic and aromatic $N$-substitutes, and it does not interfere with halogen substituent resulting in hydrodechlorination reaction.

Table 3. Selective hydrogenation of $\boldsymbol{N}$-substituted lactams derived from levulinic acid.

Levulinic acid

Reaction conditions: $1 \mathrm{mmol}$ substrate, 3 equiv. $\mathrm{H}^{-}$of $\mathrm{PhSiH}_{3}, 5 \mathrm{~mol} \% \mathrm{Cs}_{2} \mathrm{CO}_{3}, 2 \mathrm{~mL}$ MTHF, $25 \stackrel{\circ}{\circ}$; After the reaction, $2 \mathrm{~mL}$ ethanol was added to the reaction mixture and stirred at $80 \stackrel{\circ}{\circ}$ for $2 \mathrm{~h}$.

With respect to the amides bearing multi-unsaturated groups, the substrate scope was also investigated at $25{ }^{\circ} \mathrm{C}$ for the selective hydrogenation (Table 4). Either aldehyde or ketone could be hydrogenated to alcohol with yields of 97 or $94 \%$ in 1 or $2 \mathrm{~h}$, respectively (entries 1 and 3), while the amide was almost unreacted (<1\%). After reacting for 24 or $30 \mathrm{~h}$ with 4.5 equiv. $\mathrm{H}^{-}$of $\mathrm{PhSiH}_{3}$, the hydrogenation of amide to amine proceeded giving hydramine in $~ 90 \%$ yield (entries 2 and 4). This finding indicates that the initial reduction of aldehydes or ketones to corresponding silyl ethers was kinetically favorable and proceeded to completion relatively rapidly. On the other hand, hydrogenation of the amide group was most likely thermodynamically controlled, where an increase of the reaction temperature from 25 to $60{ }^{\circ} \mathrm{C}$ significantly shortened the reaction time from $24-30 \mathrm{~h}$ to $6-8 \mathrm{~h}$ with comparable hydramine yields (entries 2 and 4). Even in the presence of other unsaturated functional groups (e.g., $-\mathrm{NO}_{2}$ and $-\mathrm{CN}$ ), the amide compounds were selectively reduced at room temperature (entries 5 and 6), leaving the other functional groups intact. This unprecedented selectivity toward hydrogenates shows great potential in the controllable reduction of multiunsaturated carbonyl compounds. Thus, the reaction system permits selective reduction of amides under mild conditions, which is an enduring challenge in pharmaceutical processes 20 . Overall, the chemistries described herein thus have the potential to impact on the upgrading of biomass-derived chemicals and on fine chemical production.

Table 4. Selective reduction of amides bearing other unsaturated groups to cyclic amines

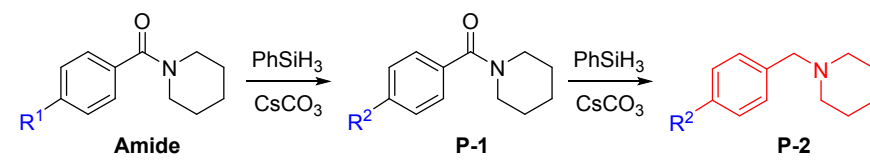

\begin{tabular}{|c|c|c|c|c|c|c|}
\hline \multirow{2}{*}{ Entry } & \multirow{2}{*}{$\mathrm{R}^{1}$} & \multirow{2}{*}{$R^{2}$} & \multirow{2}{*}{$\begin{array}{l}\text { Hydride } \\
\text { (equiv.) }\end{array}$} & \multirow{2}{*}{$\begin{array}{l}\text { Time } \\
\text { (h) }\end{array}$} & \multicolumn{2}{|c|}{ Yield (\%) } \\
\hline & & & & & P-1 & P-2 \\
\hline 1 & & $-\xi-\mathrm{CH}_{2} \mathrm{OH}$ & 1.5 & 1 & 97 & $<1$ \\
\hline & $-\xi-\mathrm{CHO}$ & & & & & \\
\hline 2 & & $-\xi-\mathrm{CH}_{2} \mathrm{OH}$ & 4.5 & $24(6)^{a}$ & $<1$ & $93(95)^{c}$ \\
\hline 3 & & & 1.5 & 2 & 94 & $<1$ \\
\hline 4 & & -30 & 4.5 & $30(8)^{a}$ & $<1$ & $87(92)^{\circ}$ \\
\hline 5 & $-\xi-\mathrm{NO}_{2}$ & $-\xi-\mathrm{NO}_{2}$ & 3 & 24 & 1 & 90 \\
\hline 6 & $-\xi-\mathrm{CN}$ & $-\xi-\mathrm{CN}$ & 3 & 24 & 2 & 82 \\
\hline
\end{tabular}

Reaction conditions: $1 \mathrm{mmol}$ substrate, $1.5-4.5$ equiv. $\mathrm{H}^{-}$of $\mathrm{PhSiH}_{3}, 5 \mathrm{~mol}^{2} \mathrm{Cs}_{2} \mathrm{CO}_{3}, 2$ $\mathrm{mL}$ MTHF, 25 oC; After the reaction, $2 \mathrm{~mL}$ ethanol was added into the reaction

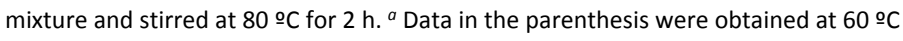
under otherwise identical conditions. 


\section{Computational study of representative reaction pathways}

Regarding the selective synthesis of GVL and 1,4-PD from EL in the presence of $\mathrm{Cs}_{2} \mathrm{CO}_{3}$ and (EtO) ${ }_{3} \mathrm{SiH}$, the in situ formed silyl ethers Si-1 and $\mathbf{S i - 2}$ were verified to be the key intermediates (vide supra), respectively. In particular, the efficiency in the consecutive addition of one to three equiv. hydrides to EL seemed essential for the formation of the silyl ethers (Fig. S22). DFT calculation was conducted to examine the free energies of the dominant products involved in the reaction pathways, and the resulting energy profiles are shown in Fig. S23. Both Si-1 and Si-2 were found to have lower free energy (-17.20 and $-15.38 \mathrm{kcal} / \mathrm{mol}$, respectively) than the starting material EL. These two silyl ethers with moderate stability can not only remain intact during the reaction process under mild conditions, but can also be further degraded to remove the siloxane moiety at elevated temperature, rendering them ideal precursors of GVL and 1,4-PD. It should be noted that EL acetal derived from Si-1 was calculated to have a higher free energy $(-2.87 \mathrm{kcal} / \mathrm{mol}$, Fig. S22), implying that the dominant barrier toward 1,4-PD from EL was the ester hydrogenation step. This finding is consistent with the experimental results, where Si-1 (precursor of GVL) can be rapidly and quantitatively formed in 0.5 $\mathrm{h}$, while approximately $6 \mathrm{~h}$ are required to obtain Si-2 (precursor of 1,4-PD).
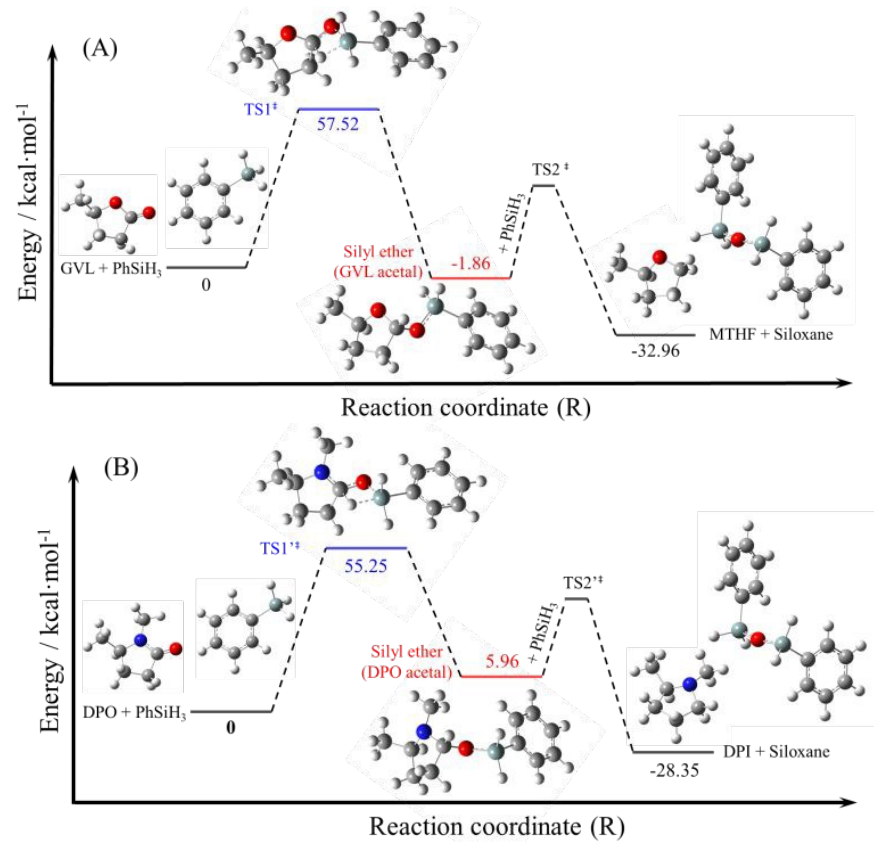

Fig. 5. DFT calculation results of silyl ether in situ formed from the lactone and lactam using $\mathbf{P h S i H}_{3}$ as $\mathbf{H}$-donor. Energy profiles for reduction of (A) $\gamma$ valerolactone (GVL) to 2-methyltetrahydrofuran (MTHF) and (B) 1,5-dimethyl-2pyrrolidinone (DPO) to 1,2-dimethylpyrrolidine (DPI) via corresponding silyl ethers. The optimized transition state (TS1) structures are shown in blue.

In addition, we note that a significant difference in product distribution was obtained when lactone and lactam were used as substrates with $\mathrm{PhSiH}_{3}$ as the hydrogen source for reduction (Fig. S24).
In the case of a lactone (e.g., GVL), a diol (1,4-PD) was prone to be obtained, while the complete reduction of lactam (e.g., 1,5-dimethyl2-pyrrolidinone (DPO)) gave cyclamine (1,2-dimethylpyrrolidine (DPI)) as the predominant product. DFT calculation demonstrated the significance of the type of silyl ethers formed in situ (i.e., GVL/DPO acetals) along with its preceding optimized transition state (TS1) in the selectivity control (Fig. 5). The TS1 free energy for initial reduction of GVL was found to be slightly higher than for initial hydrogenation of DPO (57.52 vs $55.25 \mathrm{kcal} / \mathrm{mol}$ ), indicating the need of a relatively higher energy barrier to form a GVL-derived acetal: (5methyltetrahydrofuran-2-yl)oxy phenylsilane. Moreover, the stability of this compound was higher than that of the corresponding intermediate (DPO-derived acetal), in view of their free energies ($1.86 \mathrm{vs}+5.96 \mathrm{kcal} / \mathrm{mol}$ ). This finding rationalizes the difficulty in the synthesis of MTHF from GVL, which is in agreement with the experimental results. In fact, 1,4-PD was detected to be the main product from the reduction of GVL, showing that the cyclic $\mathrm{C}-\mathrm{O}$ bond was more easily broken than the exocyclic one of the GVL acetal during the hydrosilylation process, as illustrated in Fig. S24. In contrast, the exocyclic C-O bond of the DPO-derived acetal was susceptible to cleavage, affording the cyclamine (DPI) as the principal product. The presence of competing reaction pathways dependent on the structures of in situ formed silyl ethers makes the product distribution controllable.

\section{Conclusions}

In summary, an economic and green catalytic system composed of $\mathrm{Cs}_{2} \mathrm{CO}_{3}$, hydrosilane and the bio-based solvent MTHF has been developed for room-temperature reduction of dicarbonyl compounds into monohydric esters or diols in 85-99\% yield using 1.5-3.5 equiv. $\mathrm{H}^{-}$. Especially, the cyclization/lactonization of ethyl 4-hydroxypentanoate (EHP) or its silyl ether (Si-1) formed in situ from biomass-derived ethyl levulinate (EL) can take place through a facile post-treatment process, quantitatively giving the valuable platform molecule $\gamma$-valerolactone (GVL). The process exhibits a TOF value $\left(39.2 \mathrm{~h}^{-1}\right)$ that is superior to previous results obtained using metal catalysts. By the appropriate increase of the hydrosilane dosage and by extension of the reaction time, 1,4-pentanediol (1,4-PD) instead of GVL can become the dominant product (up to $95 \%$ yield), while cyclic ether formation (selfetherification) or monohydric alcohol formation (over-hydrogenation) are absent. The in situ formation of silyl ether is most likely responsible for the pronounced performance and selectivity toward different types of carbonyl species, as demonstrated by in situ NMR and computational studies. Despite requiring longer reaction time, a variety of monohydric amides and hydroxylamines can be synthesized from corresponding dicarboxides, while the concurrent other unsaturated species remain intact. The high selectivity and benign reaction conditions render our catalytic system a promising alternative to precious metal catalysts in the specific reduction of carbonyl groups. In addition, the concept of in-situ generating labile silyl ether between the reactant and hydride bears promise in the 
switchable reduction or transformation of specific species from multifunctional groups in both biomass feedstock and relevant molecules.

\section{Experimental}

\section{Materials}

Tetrahydrofuran- $d_{8}\left(99.5\right.$ atom $\%$ D), methanol- $d_{4}$ (99.8 atom \% D), diphenylsilane- $d_{2}$ (97 atom \% D), and Amberlyst-15 (hydrogen ion form, wet) were purchased from Shanghai Sigma-Aldrich Trading Co. Ltd. Cesium carbonate $\left(\mathrm{Cs}_{2} \mathrm{CO}_{3}, 99 \%\right)$, 2-methyltetrahydrofuran (MTHF, 99\%), 18-crown-6 (99\%), triethoxysilane [( $\left.\mathrm{EtO})_{3} \mathrm{SiH}, 95 \%\right]$, phenylsilane $\left(\mathrm{PhSiH}_{3}, 97 \%\right)$, ethyl levulinate (EL, 99\%), $\gamma$-valerolactone (GVL, 98\%), 1,4-pentanediol (1,4-PD, 99\%), naphthalene (99\%), and xylene (99\%) were purchased from Beijing InnoChem Science \& Technology Co., Ltd.

\section{Reduction of multi-unsaturated carbonyl compounds}

All the reduction reactions were carried out in Ace pressure tubes (10 $\mathrm{mL}$ ). In a typical procedure, $1 \mathrm{mmol}$ carbonyl compound, 1-5.5 equiv. $\mathrm{H}^{-}$of hydrosilane, $5 \mathrm{~mol} \% \mathrm{Cs}_{2} \mathrm{CO}_{3}$, and $2 \mathrm{~mL}$ MTHF were added into the tube. After stirring ( $500 \mathrm{rpm})$ at room temperature $\left(25^{\circ} \mathrm{C}\right)$ for a specific reaction time, $2 \mathrm{~mL}$ ethanol was added into the reaction mixture and stirring continued at $80 \stackrel{\circ}{ } \mathrm{C}$ for another $2 \mathrm{~h}$. The resulting solution was collected and subjected to product analysis.

\section{Product analysis}

Dominant products were identified by GC-MS (Agilent $6890 \mathrm{~N}$ combined with $5973 \mathrm{MS}$ ), whereas the quantification of liquid products was performed by GC (Agilent 7890B) fitted with flame ionization detector (FID) and HP-5 column (30 $\mathrm{m} \times 0.320 \mathrm{~mm} \times 0.25$ $\mu \mathrm{m})$ using naphthalene as internal standard and referring to standard curves. The content of formate was determined by ${ }^{1} \mathrm{H}$ NMR using xylene as an internal standard.

\section{NMR spectroscopic study}

${ }^{1} \mathrm{H},{ }^{13} \mathrm{C}$ and $2 \mathrm{D}{ }^{1} \mathrm{H}-{ }^{13} \mathrm{C}$ HSQC NMR spectra of the liquid mixtures were obtained with normal hydrosilanes in deuterated solvents (typically, MTHF- $d_{10}$ ) or in protonated solvents containing 5\% DMSO$d_{6}$ as lock substance on a Bruker Avance III $800 \mathrm{MHz}$ spectrometer equipped with a $\mathrm{TCl}$ cryoprobe. Ex situ samples of reaction progress were obtained by quenching reactions with methanol- $d_{4}$ at indicated times. For the isotope-labeling study, ${ }^{1} \mathrm{H},{ }^{13} \mathrm{C}, \mathrm{DEPT}-135$ and ${ }^{1} \mathrm{H}-{ }^{13} \mathrm{C}$ HSQC NMR spectra of the reaction mixtures, which were obtained using deuterium reagents (diphenylsilane- $d_{2}$ and THF- $d_{8}$ with or without $\mathrm{CD}_{3} \mathrm{OD}$ post-treatment), were recorded on a JEOL-ECX 500 NMR spectrometer.

\section{Conflicts of interest}

There are no conflicts to declare.

\section{Acknowledgements}

Journal Name
This work is financially supported by the National Natural Science Foundation of China $(21576059,21666008)$, Fok Ying-Tong Education Foundation (161030), Guizhou Science \& Technology Foundation ([2018]1037, [2017]5788), and Key Technologies R\&D Program of China (2014BAD23B01). We acknowledge the NMR center DTU (Denmark) for recording NMR spectra, and Institute of Chemistry (CAS) for DFT calculation. S.S. thanks the Department of Biotechnology (Government of India) New Delhi, India for support.

\section{Notes and references}

1. a) D. Wang, D. Astruc, Chem. Rev. 2015, 115, 6621-6686; b) J.H. Xie, S.F. Zhu, Q.L. Zhou, Chem. Rev. 2011, 111, 1713-1760; c) J. Pritchard, G.A. Filonenko, R. van Putten, E.J.M. Hensen, E.A. Pidko, Chem. Soc. Rev. 2015, 44, 3808-3833.

2. a) R. M. Bullock, Science 2013, 342, 1054-1055; b) A. Corma, P. Serna, Science, 2006, 313, 332-334; c) P. Ryabchuk, G. Agostini, M.M. Pohl, H. Lund, A. Agapova, H. Junge, K. Junge, M. Beller, Sci. Adv. 2018, 4, eaat0761.

3. a) K. Manna, T. Zhang, M. Carboni, C.W. Abney, W. Lin, J. Am. Chem. Soc. 2014, 136, 13182-13185; b) H. Li, Z. Fang, R.L. Smith, S. Yang, Prog. Energ. Combust. 2016, 55, 98-194; c) M. Naruto, S. Saito, Nat. Commun. 2015, 6, 8140; d) T.J. Korstanje, J.I. van der Vlugt, C.J. Elsevier, B. de Bruin, Science 2015, 350, 298-302; e) K. Yuan, T. Song, D. Wang, X. Zhang, X. Gao, Y. Zou, H. Dong, Z. Tang, W. Hu, Angew. Chem. Int. Ed. 2018, 57, 5708-5713; f) R.C. Cammarota, C.C. Lu, J. Am. Chem. Soc. 2015, 137, 12486-12489; g) L. Wang, E. Guan, J. Zhang, J. Yang, Y. Zhu, Y. Han, M. Yang, C. Cen, G. Fu, B.C. Gates, F.S. Xiao, Nat. Commun. 2018, 9, 1362.

4. a) C. Pilar Jiménez-Gómez, J.A. Cecilia, D. Durán-Martín, R. Moreno-Tost, J. Santamaría-González, J. Mérida-Robles, R. Mariscal, P. Maireles-Torres, J. Catal. 2016, 336, 107-115; b) G.W. Huber, J.N. Chheda, C.J. Barrett, J.A. Dumesic, Science 2005, 308, 1446-1450; c) C. Zhao, Y. Kou, A.A. Lemonidou, X. Li, J.A. Lercher, Angew. Chem. Int. Ed. 2009, 48, 3987-3990.

5. a) Q. Meng, M. Hou, H. Liu, J. Song, B. Han, Nat. Commun. 2017, 8, 14190; b) M. Tamura, N. Yuasa, J. Cao, Y. Nakagawa, K. Tomishige, Angew. Chem. Int. Ed. 2018, 57, 8058-8062.

6. a) W. Liu, Y. Jiang, K.H. Dostert, C.P. O'Brien, W. Riedel, A. Savara, S. Schauermann, A. Tkatchenko, Sci. Adv. 2017, 3, e1700939; b) Y. Zhu, H. Qian, B.A. Drake, R. Jin, Angew. Chem. Int. Ed. 2010, 49, 1295-1298.

7. a) C.O. Tuck, E. Pérez1, I.T. Horváth, R.A. Sheldon, M. Poliakoff, Science 2012, 337, 695-699; b) Y.S. Jang, B. Kim, J.H. Shin, Y.J. Choi, S. Choi, C.W. Song, J. Lee, H.G. Park, S.Y. Lee, Biotechnol. Bioeng. 2012, 109, 2437-2459; c) H. Li, A. Riisager, S. Saravanamurugan, A. Pandey, R.S. Sangwan, S. Yang, R. Luque, ACS Catal. 2018, 8, 148-187; d) H. Li, R.L. Smith, Nat. Catal. 2018, 1, 176-177.

8. a) Y. Román-Leshkov, C.J. Barrett, Z.Y. Liu, J.A. Dumesic, Nature 2007, 447, 982-985; b) J.N. Chheda, G.W. Huber, J.A. Dumesic, Angew. Chem. Int. Ed. 2007, 46, 7164-7183; c) D.M. Alonso, S.G. Wettstein, J.A. Dumesic, Green Chem. 2013, 15, 584-595.

9. a) W. Deng, Y. Wang, N. Yan, Curr. Opin. Green Sustain. Chem. 2016, 2, 54-58; b) H. Li, Z. Fang, J. Luo, S. Yang, Appl. Catal. B: Environ. 2017, 200, 182-191.

10. a) Z. Zhang, ChemSusChem 2016, 9, 156-171; b) B. Banerjee, R. Singuru, S.K. Kundu, K.Dhanalaxmi, L. Bai, Y. Zhao, B.M. Reddy, A. Bhaumik, J. Mondal, Catal. Sci. Technol. 2016, 6, 5102-5115; c) S. Pendem, I. Mondal, A. Shrotri, B. S. Rao, N. Lingaiah, J. Mondal, Sustainable Energy Fuels 2018, 2, 1516-1529; d) K. Dhanalaxmi, 
R. Singuru, S. Mondal, L. Bai, B. M. Reddy, A. Bhaumik, J. Mondal, ACS Sustainable Chem. Eng. 2017, 5, 1033-1045; e) D. Ren, X. Wan, F. Jin, Z. Song, Y. Liu, Z. Huo, Green Chem. 2016, 18, 5999-6003; f) T. Mizugaki, Y. Nagatsu, K. Togo, Z. Maeno, T. Mitsudome, K. Jitsukawa, K. Kaneda, Green Chem. 2015, 17, 5136-5139; g) J. Cui, J. Tan, Y. Zhu, F. Cheng, ChemSusChem 2018, 11, 1316-1320; h) S. C. Patankar, G. D. Yadav, ACS Sustainable Chem. Eng. 2015, 3, 2619-2630.

11. a) S.G. Wettstein, D.M. Alonso, Y. Chong, J.A. Dumesic, Energy Environ. Sci. 2012, 5, 8199-8203; b) W. Luo, M. Sankar, A.M. Beale, Q. He, Christopher J. Kiely, Pieter C.A. Bruijnincx, B.M. Weckhuysen, Nat. Commun. 2015, 6, 6540; c) A. Primo, P. Concepción, A. Corma, Chem. Commun. 2011, 47, 3613-3615; d) T. Mizugaki, Y. Nagatsu, K. Togo, Z. Maeno, T. Mitsudome, K. Jitsukawa, K. Kaneda, Green Chem. 2015, 17, 5136-5139; e) D. Addis, S. Das, K. Junge, M. Beller, Angew. Chem. Int. Ed. 2011, 50 6004-6011; f) A. Volkov, K.P.J. Gustafson, C.W. Tai, O. Verho, J.E. Bäckvall, H. Adolfsson, Angew. Chem. Int. Ed. 2015, 54, 51225126; g) H. Li, W. Zhao, Z. Fang, Appl. Catal. B: Environ. 2017, 215, 18-27.

12. F. Lehmann, Synlett 2004, 2447-2448.

13. a) X. Y. Li, R. Shang, M. C. Fu, Y. Fu, Green Chem. 2015, 17, 27902793; b) W. Zhao, T. Yang, H. Li, W. Wu, Z. Wang, C. Fang, S. Saravanamurugan, S. Yang, ACS Sustainable Chem. Eng. 2017, 5, 9640-9644; c) X. F. Liu, C. Qiao, X. Y. Li, L. N. He, Green Chem. 2017, 19, 1726-1731; d) H. Li, W. Zhao, A. Riisager, S. Saravanamurugan, Z. Wang, Z. Fang, S. Yang, Green Chem. 2017, 19, 2101-2106; e) C. Wu, X. Luo, H. Zhang, X. Liu, G. Ji, Z. Liu, Z. Liu, Green Chem. 2017, 19, 3525-3529; f) H. Li, W. Zhao, S. Saravanamurugan, W. Dai, J. He, S. Meier, S. Yang, A. Riisager, Commun. Chem. 2018, 1, 32; g) C. Xu, B. Huang, T. Yan, M. Cai, Green Chem. 2018, 20, 391-397; h) R. A. Pramudita, K. Motokura, Green Chem. 2018, DOI: 10.1039/C8GC02052C.

14. a) T. Mizugaki, Y. Nagatsu, K. Togo, Z. Maeno, T. Mitsudome, K. Jitsukawa, K. Kaneda, Green Chem. 2015, 17, 5136-5139; b) T. Mizugaki, K. Togo, Z. Maeno, T. Mitsudome, K. Jitsukawa, K. Kaneda, ACS Sustain. Chem. Eng. 2016, 4, 682-685; c) D. Ren, X. Wan, F. Jin, Z. Song, Y. Liu, Z. Huo, Green Chem. 2016, 18, 59996003.

15. a) K. K. Senapati, Polymethylhydrosiloxane (PMHS), Synlett 2005, 12, 1960-1961; b) D. B. Nale, B. M. Bhanage, Green Chem. 2015, 17, 2480-2486; c) J. A. Caetano, A. C. Fernandes, Green Chem. 2018, 20, 2494-2498.

16. M. Chia, Y. J. Pagán-Torres, D. Hibbitts, Q. Tan, H. N. Pham, A. K. Datye, M. Neurock, R. J. Davis, J. A. Dumesic, J. Am. Chem. Soc. 2011, 133, 12675-12689.

17. S. Wang, H. Huang, C. Bruneau, C. Fischmeister, ChemSusChem 2017, 10, 4150-4154;

18. G. Gao, P. Sun, Y. Li, F. Wang, Z. Zhao, Y. Qin, F. Li, ACS Catal. 2017, 7, 4927-4935.

19. a) J. R. Cabrero-Antonino, E. Alberico, K. Junge, H. Junge, M. Beller, Chem. Sci. 2016, 7, 3432-3442; b) N. M. Rezayee, D. C. Samblanet, M. S. Sanford, ACS Catal. 2016, 6, 6377-6383; c) V. Papa, J. R. Cabrero-Antonino, E. Alberico, A. Spanneberg, K. Junge, H. Junge, M. Beller, Chem. Sci. 2017, 8, 3576-3585.

20. a) J.M. Woodley, Trend. Biotechnol. 2008, 26, 321-327; b) N. L. Lampland, M. Hovey, D. Mukherjee, A.D. Sadow, ACS Catal. 2015, 5, 4219-4226; c) Y.Q. Zou, S. Chakraborty, A. Nerush, D. Oren, Y. Diskin-Posner, Y. Ben-David, D. Milstein, ACS Catal. 2018, 8, 8014-8019. 


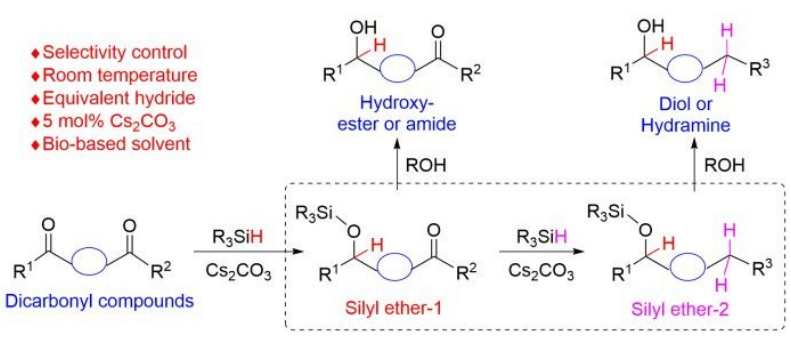

A simple and robust catalytic system is described for the controllable conversion of biomass-derived chemicals. 